\title{
Using Standardized Patient Assessments to Evaluate a Health Literacy Curriculum
}

Gail S. Marion, PhD; Jade M. Hairston, MA; Stephen W. Davis, MA; Julienne K. Kirk, PharmD

\begin{abstract}
BACKGROUND AND OBJECTIVES: Patients' health literacy is a growing concern as patients are expected to perform more self-care. While many US schools implement health literacy in their curricula, time spent on the topic ranges from 0 to $\mathbf{8}$ hours and is largely didactic. Evaluation of health literacy skills is not well defined. The effectiveness of a health literacy curriculum for third-year medical students was evaluated by two standardized patients assessments (SPAs).
\end{abstract}

METHODS: All third-year medical students complete a required 4-week clerkship in family medicine. After participating in seminars on patient-centered communication, health literacy, mindfulness, implicit bias, and chronic disease management, students complete SPA-1. Students also work in two teambased teaching clinics with chronic disease patients with limited health literacy and receive faculty feedback. At week 4 , students complete SPA-2. Six raters evaluated all video-recorded SPA performances using the Common Ground validated instrument and a tailored health literacy skills checklist.

RESULTS: Using SPAs and reliably-trained nonclinical raters is an effective method for training and evaluating students about health literacy. Two classes (2013 and 2015) had significant improvement in Common Ground core skills from SPA-1 to SPA-2. For all classes, a small but significant increase in student use of health literacy checklist was seen from SPA-1 to SPA-2.

CONCLUSIONS: Didactic sessions prepare students to demonstrate competence on Common Ground and health literacy skills. Improvements in students' health literacy and communication skills are feasible in a 4-week clerkship utilizing the curriculum and evaluation process described.

(Fam Med. 2018;50(1):52-7.)

doi: 10.22454/FamMed.2018.539107

ncreasingly complex health systems necessitate patients learn and routinely perform self-care skills. Recognizing and improving patients' health literacy has emerged as a central health concern. The Institute of Medicine defines health literacy as "the degree to which individuals have the capacity to obtain, in rural areas, experience poorer health and higher mortality.3,4

Standardized patient assessments (SPAs) provide for direct observation, training, and evaluation of studentpatient interactions during histories, physical examinations, and wrap-up. SPAs offer objective data on learner performance. ${ }^{5,6}$ The SPA performance evaluation is enhanced when paired with evaluations by trained raters. ${ }^{7}$ Student performance in a 32-hour health literacy curriculum using interactive seminars, patient-centered communication, and health literacy skills was assessed with SPAs.

\section{Methods}

Participants included 435 third-year medical students completing a required 4-week clerkship in family medicine at the Wake Forest School of Medicine (WFSM) for the graduating classes of 2013 to 2016. Participants signed informed consents approved by the WFSM Institutional Review Board. In week 1, students attend five case-based seminars focused on recognizing problems and solutions associated with low health literacy (Table 1). ${ }^{8-23}$ The curriculum includes two team-based teaching clinics (TBTCs). Paired students participate in the care of faculty members' continuity patients with

From Wake Forest School of Medicine, Department of Family and Community Medicine, Winston-Salem, NC. 
Table 1: Components of Health Literacy Curriculum

\begin{tabular}{|c|c|c|}
\hline \multicolumn{3}{|c|}{$\begin{array}{l}\text { Week 1: Five Interactive Case-Based Seminars Focused on Recognizing } \\
\text { Problems and Solutions Associated With Low Health Literacy }\end{array}$} \\
\hline Seminar & Instruments or Resources Used & Brief Description \\
\hline $\begin{array}{l}\text { Common } \\
\text { Ground } \\
\text { Seminar }\end{array}$ & $\begin{array}{l}\text { Common Ground Communication Model, }{ }^{8} 6 \text { core skills: } \\
\text { (1) Rapport Building; (2) Agenda Setting; (3) Information } \\
\text { Management; (4) Active Listening; (5) Addressing Feelings; } \\
\text { (6) Reaching Common Ground (wrap-up). } \\
\text { Skill scores range from 1 (ineffective) to 5 (highly effective) } \\
\text { http://www.stfm.org/fmhub/fm2004/March/Forrest189.pdf }\end{array}$ & $\begin{array}{l}\text { - Evaluation of a standardized video of a } \\
\text { physician and a low health literacy patient } \\
\text { with diabetes using the Common Ground } \\
\text { instrument } \\
\text { - Learners self and peer assess and } \\
\text { evaluators give feedback }\end{array}$ \\
\hline $\begin{array}{l}\text { Health } \\
\text { Literacy } \\
\text { Seminar }\end{array}$ & $\begin{array}{l}\text { Agency for Healthcare Research Quality (AHRQ) } \\
\text { Health Literacy Universal Precautions Toolkit. }{ }^{10} \\
\text { - } 21 \text { tools addressing communication, self-management, } \\
\text { empowerment and support systems } \\
\text { - Appendices of }>25 \text { resources } \\
\text { https://www.ahrq.gov/professionals/quality-patient-safety/ } \\
\text { quality-resources/tools/literacy-toolkit/healthlittoolkit2.html } \\
\text { Newest Vital Sign Instrument, }{ }^{11,12} \text { 6-item validated } \\
\text { instrument for patients, related to understanding of } \\
\text { information on a food label } \\
\text { https://www.pfizer.com/files/health/nvs_flipbook_english_ } \\
\text { final.pdf }\end{array}$ & $\begin{array}{l}\text { - Students review toolkit prior to the } \\
\text { session } \\
\text { - Highlights problems and solutions to } \\
\text { effective patient care and assessing health } \\
\text { literacy in the clinic } \\
\text { - Students present two stories describing } \\
\text { effective and ineffective health literacy } \\
\text { experiences with a provider and patient } \\
\text { from their first years of medical school. }{ }^{13} \\
\text { - They discuss patient outcomes and missed } \\
\text { opportunities for effective communication }\end{array}$ \\
\hline $\begin{array}{l}\text { Implicit Bias } \\
\text { Seminar }\end{array}$ & $\begin{array}{l}\text { Implicit Association Test (IAT) }{ }^{14} \text { validated instrument } \\
\text { measuring response times to determine unconscious biases. } \\
\text { If an individual associates a group with negative attributes, } \\
\text { they will be slower to pair that group with positive words }{ }^{15,16} \\
\text { https://faculty.washington.edu/agg/pdf/Gwald_McGh_Schw__ } \\
\text { JPSP_1998.OCR.pdf }\end{array}$ & $\begin{array}{l}\text { - Students view images of "young" or "old" } \\
\text { people (one IAT example) and pair them } \\
\text { with negative or positive words } \\
\text { - They debrief results } \\
\text { - They watch two videos depicting implicit } \\
\text { bias with a patient }\end{array}$ \\
\hline $\begin{array}{l}\text { Mindfulness } \\
\text { Training }\end{array}$ & $\begin{array}{l}\text { 3-hour sessions to increase real-time empathy, self- } \\
\text { awareness, self-reflection, and field awareness in the clinical } \\
\text { encounter } \\
\text { Voice-over video PowerPoints }\end{array}$ & $\begin{array}{l}\text { - Provides users with knowledge, skill } \\
\text { review, and opportunities for reflection. } \\
\text { Fosters learning about complex } \\
\text { communication and relationship } \\
\text { challenges }^{17}\end{array}$ \\
\hline $\begin{array}{l}\text { Diabetes } \\
\text { Care }\end{array}$ & American Association Standard of Care Guidelines ${ }^{18-22}$ & $\begin{array}{l}\text { - Students identify patient barriers and } \\
\text { how providers detail alternatives and } \\
\text { solutions } \\
\text { - Discussion of diabetes outcomes aimed at } \\
\text { a low health literacy patient with type } 2 \\
\text { diabetes and depression }\end{array}$ \\
\hline \multicolumn{3}{|c|}{ Week 2 (Interpreter Training, SPA 1) } \\
\hline $\begin{array}{l}\text { Interpreter } \\
\text { Training }\end{array}$ & $\begin{array}{l}\text { 12-item checklist of skills rated on a scale of } 0 \text { to } 2(0=\text { not } \\
\text { performed, } 1=\text { partially performed, } 2=\text { performed): } \\
\text { (1) Gave instructions and expectations to the interpreter } \\
\text { at beginning of visit; (2) Did not allow side conversation; } \\
\text { (3) Did not talk in ling units of speech; (4) Did not allow } \\
\text { the interpreter to sit in the way of the patient and doctor; } \\
\text { (5) Did not allow the interpreter to paraphrase or omit } \\
\text { information; (6) Did not allow the interpreter to use his/ } \\
\text { her own ideas; (7) Checked for patient's understanding by } \\
\text { asking patient to repeat instructions; (8) Spoke directly to } \\
\text { the patient, not the interpreter; (9) Listened to the patient } \\
\text { and interpreter and observed their verbal and non-verbal } \\
\text { communication; (10) Did not allow the interpreter to take } \\
\text { control of the visit; (11) The health care provider did not } \\
\text { become impatient because the interview took longer/ } \\
\text { was more difficult; (12) Thanked the interpreter for their } \\
\text { services. }\end{array}$ & $\begin{array}{l}\text { - 90-minute interview with a Spanish- } \\
\text { language Standardized Patient (SP) and } \\
\text { certified interpreters, who provide feedback } \\
\text { to students using a } 12 \text {-item checklist. }{ }^{23}\end{array}$ \\
\hline
\end{tabular}


Table 1 (continued)

\begin{tabular}{|c|c|c|}
\hline \multicolumn{3}{|c|}{ Week 2 (Interpreter Training, SPA 1) } \\
\hline Seminar & Instruments or Resources Used & Brief Description \\
\hline SPA 1 & $\begin{array}{l}\text { Simulated patient (SP) chart } \\
\text { Student-created SOAP note on patient } \\
\text { Rater-evaluation of SPA video } \\
\text { Trained provider feedback to student on SPA encounter } \\
\text { - Students expected to address diabetes diagnosis by } \\
\text { "breaking the news" to SP, addressing feelings and } \\
\text { expectations, and developing a management plan together } \\
\text { with SP. }\end{array}$ & $\begin{array}{l}\text { SP with symptoms of diabetes and not } \\
\text { aware of condition (consumes soda, fast } \\
\text { food and does not exercise). }\end{array}$ \\
\hline \multicolumn{3}{|c|}{ Week 2-4 (Team-Based Teaching Clinic-2 Sessions) } \\
\hline $\begin{array}{l}\text { Team-Based } \\
\text { Teaching } \\
\text { Clinics } \\
\text { (TBTC) }\end{array}$ & $\begin{array}{l}\text { Common Ground Instrument (faculty facilitators were } \\
\text { trained in using the Common Ground and health literacy } \\
\text { skills) } \\
\text { Students reviewed patient's chart, performed a focused } \\
\text { history, physical and patient wrap-up in real time with } \\
\text { faculty. } \\
\text { Students completed a written plan using concise, bulleted } \\
\text { phrases to share with patient during the wrap-up to } \\
\text { facilitate and assess patient understanding. }\end{array}$ & $\begin{array}{l}\text { Students practiced seminar components in } \\
\text { faculty members' continuity patients with } \\
\text { chronic disease. Students, supervised by } \\
\text { faculty, cared for patients in 4-hour clinical } \\
\text { session, with immediate feedback. Patient } \\
\text { wrap-up included explaining impressions } \\
\text { using plain talk, and checking for } \\
\text { agreement, feasibility and understanding } \\
\text { using teach-back method. }\end{array}$ \\
\hline \multicolumn{3}{|c|}{ Week 4 (SPA 2) } \\
\hline SPA 2 & $\begin{array}{l}\text { Simulated patient (SP) chart } \\
\text { Student-created SOAP note on patient } \\
\text { Rater-evaluation of SPA video } \\
\text { Trained provider feedback to student on SPA encounter - } \\
\text { (Ideally, student identifies supplement as potential cause for } \\
\text { increased blood pressure.) }\end{array}$ & $\begin{array}{l}\text { SP with hypertension and hyperlipidemia. } \\
\text { At regular check-up, blood pressure is } \\
\text { high. SP exercises regularly and consumes } \\
\text { healthy diet. SP mentions taking herbal } \\
\text { supplement to improve energy. }\end{array}$ \\
\hline
\end{tabular}

chronic diseases in 4-hour TBTCs. Students are evaluated during two 20-minute SPAs that include a focused interview, exam, treatment plan, and completing a "subjective, objective, assessment, and plan" (SOAP) note.

\section{Training and Instruments}

Eight faculty received training in the Common Ground model and health literacy skills curriculum. The Common Ground instrument addresses six criteria-based, patient-centered skills. Interview skills are measured by a global rating that incorporates comprehensive criteria for SPA (Table 2). In the original validation, the interrater reliability was 0.85 for the global rating and 0.92 for the overall checklist assessment. ${ }^{8}$

To evaluate health literacy competency, we used seven questions from the US Health Resources and Services Administration (HRSA) health literacy website (Table 3). ${ }^{24}$ Reliably trained raters scored students' performance for SPA via digital recordings. Three times annually, raters received iterative feedback to assure that scoring was consistent with benchmarking.

\section{Data Collection and Analysis}

After video recording, SPA data was deidentified. Reliably trained raters evaluated both performances using the Common Ground instrument ${ }^{8}$ and completed the health literacy skills checklist (Table 3). Paired Common Ground scores and health literacy checklists were evaluated for differences between SPA-1 and SPA2 using SPSS. ${ }^{25}$ Repeated measures analyses of variance were performed separately for the Common Ground and health literacy measures. SPA1 vs SPA-2 was a within-subject variable and student class was a between-subject variable. Pearson's correlation was used to correlate Common Ground global scores and health literacy scores.

\section{Results}

Participants were medical students in the classes of 2013 ( $\mathrm{n}=109), 2014$ $(\mathrm{n}=120), 2015(\mathrm{n}=107)$, and $2016(\mathrm{n}=$ 98). Students had an average age of 26.8 years (range 24 to 43 ), and $54 \%$ of students were men. Overall, $72 \%$ of students were white, $11 \%$ African American, 8\% Asian, and 9\% other. For the classes of 2013, 2015, and 2016,314 of 338 (93\%) videos had both SPA sessions (data not captured for class of 2014 SPA-2).

A health literacy curriculum with SPAs using trained raters near the beginning and at the end of the clerkship was implemented. After SPA1 , and receiving 8 hours of training with health literacy and communication components, students' global scores were in the low competent range on Common Ground and on the health literacy skills checklist. Common Ground scores analyses revealed a main effect of class, a main effect of first and second SPA sessions, and an interaction between 
Table 2: Examples of Common Ground ${ }^{8}$ Skills: "Active Listening", "Reaching Common Ground", and "Overall Interview" Criteria ${ }^{1}$

\begin{tabular}{|c|c|}
\hline \multicolumn{2}{|r|}{ Active Listening } \\
\hline Score Example & Criteria \\
\hline 3 & $\begin{array}{l}\text { Demonstrates some interest in the patient's perspective on illness (PPI) through occasional } \\
\text { exploration of clues (efforts may not be effective). May not pick up on clues but rather asks about the } \\
\text { patient's ideas. }\end{array}$ \\
\hline 4 & $\begin{array}{l}\text { Demonstrates genuine interest in the PPI by using active listening at least part of the time. Does } \\
\text { explore the clues initially, but not always fully. Once identified, PPI will be partially addressed with } \\
\text { some elements of acknowledgement, normalization, and building a plan based on the PPI. }\end{array}$ \\
\hline \multicolumn{2}{|r|}{ Reaching Common Ground } \\
\hline Score Example & Criteria \\
\hline 3 & $\begin{array}{l}\text { Partial or minimal understanding of patient's knowledge. Provides information with general clarity. } \\
\text { May include some jargon. Some effort to determine understanding and/or feasibility (uses close- } \\
\text { ended question). }\end{array}$ \\
\hline 4 & $\begin{array}{l}\text { Plan begins with some understanding of patient's knowledge and perspective. Explains clearly with } \\
\text { only occasional use of jargon. Checks for understanding and feasibility. }\end{array}$ \\
\hline \multicolumn{2}{|r|}{ Overall Interview } \\
\hline Score & Criteria \\
\hline 1 & $\begin{array}{l}\text { Inadequate communication skills; likely to create significant clinical problems (patient dissatisfaction } \\
\text { or confusion). }\end{array}$ \\
\hline 2 & $\begin{array}{l}\text { Uses some communication skills effectively and others ineffectively; certain areas of communication } \\
\text { might cause clinical problems (patient dissatisfaction or confusion). }\end{array}$ \\
\hline 3 & $\begin{array}{l}\text { Uses most communication skills effectively; some interview behaviors present which, if modified, } \\
\text { could lead to an even more effective impact on a real encounter. }\end{array}$ \\
\hline 4 & $\begin{array}{l}\text { Uses all communication skills effectively; minor suggestions for change are noted which are unlikely } \\
\text { to have measurable importance on encounter. }\end{array}$ \\
\hline 5 & $\begin{array}{l}\text { At the level of an experienced clinician who is expert in using all communications skills effectively. } \\
\text { Skills demonstrated such that a patient would likely note such skills to friends and family. }\end{array}$ \\
\hline
\end{tabular}

${ }^{1}$ For each skill, participants receive a score rated on a scale of 1 to 5 . The average scores were between 3 and 4 .

Table 3: Health Literacy Skills Checklist: Tool Used by Raters During SPA ${ }^{1,2}$

Identifies "red flags" and risk factors for limited health literacy

Uses newest vital sign scores to tailor dialogue with patients (patient's score is 3 . Score of 0-1 suggests high likelihood (50\% or more) of limited health literacy, score of 2-3 indicates the possibility of limited health literacy, score of 4-6 almost always indicates adequate health literacy)

Initially tailors information given to the patient to address their health literacy level and cultural background Presents manageable amounts of information in plain language

Summarizes patient education and follow-up plan based on patient's level of understanding

Utilizes the interactive technique to verify patient understanding of information given them ("Teach-Back method")

Adjusts instructional methods appropriate to the patient's level of understanding based on the teach-back

${ }^{1}$ Tool used by reliably trained raters via the digital recording evaluation of standardized patient assessments (SPA).

${ }^{2}$ Each item was rated on a scale of 0 to 2 (0: Not performed, 1: Partially performs, 2: Performs well) for a total score of 0 to 14. 
class and session (Table 4). The classes of 2013 and 2015 showed significant improvements from the first to the second SPA session (Table 4). The class of 2016 improved, but the difference was not significant.

Health literacy scores showed significant main effects of class and SPA-1 versus SPA-2 (Table 5). Post hoc tests showed all classes had improved scores for health literacy skills from SPA-1 to SPA-2, attributed to communication skills. Post hoc examination of the main effect of class (SPA scores averaged across both sessions) revealed that the class of 2013 had higher health literacy scores than the other classes combined across both SPAs. The class of 2015 had higher average scores than the class of 2016. The Common Ground instrument scores were positively correlated with health literacy scores at each SPA session (Pearson correlation .45 SPA-1, .50 SPA-2).

Table 4: Common Ground Measures for SPA

\begin{tabular}{|l|c|c|c|c|c|c|c|}
\hline & & \multicolumn{2}{|c|}{ SPA Session 1 } & \multicolumn{2}{c|}{ SPA Session 2 } & \multicolumn{2}{c|}{ Total } \\
\hline & $\mathbf{N}$ & Mean & SD & Mean & SD & Mean & SD \\
\hline Class of 2013 & 109 & 3.27 & .61 & 3.68 & .52 & 3.47 & .44 \\
\hline Class of $2014^{1}$ & 120 & 3.32 & .53 & -- & -- &. & - \\
\hline Class of 2015 & 107 & 3.13 & .61 & 3.46 & .61 & 3.29 & .44 \\
\hline Class of 2016 & 98 & 3.35 & .55 & 3.49 & .54 & 3.42 & .45 \\
\hline $\begin{array}{l}\text { Total (2013, 2015, } \\
\text { and 2016) }\end{array}$ & $314^{2}$ & 3.25 & .60 & 3.54 & .56 & 3.40 & .45 \\
\hline
\end{tabular}

${ }^{1}$ Due to financial constraints and administrative decisions by the clerkship director, the class of 2014 had SPA session 1 only and was not included in the total above or in the analysis.

${ }^{2}$ Out of the total 338 videos for classes 2013, 2015, and 2016, Common Ground measures were not available for 24 due to either no consent, technical difficulties, absences or unmatched pairs.

Repeated measures ANOVA: Main effect of Class $(P=.009)$, Main effect of Time $(P=.000)$, Interaction of Class by Time of Assessment $(P=.027)$

Post hoc comparisons (Bonferroni):

SPA 1 to SPA 2 class of $2013 P=.000$, class of $2015 P=.000$, class of $2016 P=.065$.

Post hoc comparisons (Bonferroni):

SPA session 1 class of $2016>$ class of $2015(P=.023)$

SPA session 2 class of $2013>$ class of $2015(P=.011)$

Table 5: Health Literacy Measures for SPAs

\begin{tabular}{|c|c|c|c|c|c|c|c|}
\hline & & \multicolumn{2}{|c|}{ SPA Session 1} & \multicolumn{2}{|c|}{ SPA Session 2} & \multicolumn{2}{|c|}{ Total } \\
\hline & $\mathbf{N}$ & Mean & SD & Mean & SD & Mean & SD \\
\hline Class of 2013 & 104 & 7.60 & 3.48 & 10.28 & 3.04 & 8.94 & 2.29 \\
\hline Class of $2014^{1}$ & 120 & 7.15 & 3.49 & -- & -- & -- & -- \\
\hline Class of 2015 & 104 & 6.98 & 3.61 & 8.43 & 3.52 & 7.71 & 2.64 \\
\hline Class of 2016 & 99 & 6.06 & 3.77 & 7.53 & 3.24 & 6.79 & 2.70 \\
\hline $\begin{array}{l}\text { Total }(2013,2015 \text { and } \\
2016)\end{array}$ & $307^{2}$ & 6.89 & 3.67 & 8.77 & 3.46 & 7.83 & 2.70 \\
\hline
\end{tabular}

${ }^{1}$ Due to financial constraints and administrative decisions by the clerkship director, the class of 2014 had SPA session 1 only and was not included in the total above or in the analysis.

${ }^{2}$ Out of the total 338 videos for classes 2013, 2015 and 2016, health literacy measures were not available for 31 due to either no consent, technical difficulties, absences or unmatched pairs.

Repeated measures analysis: main effect of class $P=.000$, main effect of time $P=.000$.

Post hoc comparisons for class (Bonferroni): class of $2013>2015(P=.002)$, class of $2013>2016(P=.000)$, class of $2015>2016(P=.034)$.

Post hoc comparisons for time SPA 1 to SPA 2 (Bonferroni): class of $2013 P=.000$, class of $2015 P=.002$, class of $2016 P=.002$. 


\section{Discussion}

Training medical students to assess health literacy is essential for effective patient communication. The curriculum offers a range of activities focused on the attitudes, knowledge, and skills for a learner to effectively create care plans with patients of diverse backgrounds and health literacy levels. The unbiased raters' assessments using a validated scale increases confidence in the results. Our pool of raters remained stable over time, maintained their enthusiasm, and demonstrated sustained ownership regarding the success of this curriculum. Between SPA sessions, students participated in two TBTCs. Thereafter, both communication and health literacy scores increased from SPA-1 to SPA-2 for the classes of 2013, 2015, and 2016.

One limitation of this research is that the clerkship directors preferred an introduction to curriculum before SPA-1 for students to learn health literacy knowledge and skills before being evaluated. Health literacy and communication seminars are provided in the first 2 days of the clerkship. While we do not have a true baseline, scores between the two SPA sessions improved significantly.

This curriculum provided a robust medical student experience designed to improve care for patients with limited health literacy. Rater training provides a structure that other medical schools could adopt to enhance their evaluation of students' skills. Other programs could use the curriculum described with only the cost of training raters and standardized patients. Since patients are expected to perform increasing self-care, learners need to know what patients understand in order to learn how to communicate effectively.

ACKNOWLEDGMENTS: We gratefully acknowledge the editorial assistance of Karen Klein, MA, in the Wake Forest Clinical and Translational Science Institute (UL1 TR001420; PI: $\mathrm{Li}$. We are deeply grateful for the sustained commitment of our video raters over the years of this project. Without their passion for this work, attention to detail, and continued willingness to be recalibrated, this project would not have been possible.
We warmly acknowledge the significant contributions that Dr Forrest Lang made to our patient-centered communications curriculum.

Financial Support: HRSA Grant D56HP20779, 5-year educational grant awarded in 2010 with a 1 -year, no-cost extension awarded in 2015 .

CORRESPONDING AUTHOR: Address correspondence to Dr Kirk, Family and Community Medicine, Wake Forest School of Medicine Medical Center Boulevard, Winston-Salem, NC 27157-1084. 336-716-2906. Fax: 336-716-8552 jkirk@wakehealth.edu.

\section{References}

1. Institute of Medicine. Report Brief. Health Literacy: A Prescription to End Confusion. Washington, DC: National Academies Press; 2004

2. Weiss BD. Health Literacy and Patient Safety: Help PatientsU. 2nd ed. Chicago: American Medical Association; 2007.

3. Berkman ND, Sheridan SL, Donahue KE Halpern DJ, Crotty K. Low health literacy and health outcomes: an updated systematic review. Ann Intern Med. 2011;155(2):97-107.

4. Sun LH. Rural Americans are more likely to die from the five top causes of death. Boston Globe. January 12, 2017. https://www.bostonglobe.com/news/nation/2017/01/12/rural-americans-are-more-likely-die-from-top-causes-death FFPY2khJWo0ivXzBmC3gqO/story.html. Accessed January, 2017.

5. Colliver JA, Swartz MH, Robbs RS, Cohen DS. Relationship between clinical competence and interpersonal and communication skills in standardized-patient assessment. Acad Med. 1999;74(3):271-274

6. Petrusa ER. Taking standardized patient-based examinations to the next level. Teach Learn Med. 2004;16(1):98-110.

7. Marion GS, Davis SD, Hairston JM, et al Using standardized patient assessments to evaluate a health literacy curriculum. Poster presented at STFM Conference on Medical Education; Feb. 5-8, 2015; Atlanta, Georgia.

8. Lang F, McCord R, Harvill L, Anderson DS Communication assessment using the common ground instrument: psychometric properties. Fam Med. 2004;36(3):189-198.

9. Carney PA, Palmer RT, Fuqua Miller M, et al Tools to assess behavioral and social science competencies in medical education; a systematic review. Acad Med. 2016;91(5):730-742.

10. Brega AG, Barnard J, Mabachi NM, et al. Health Literacy Universal Precautions Toolkit. 2nd ed. Rockville, MD: Agency for Healthcare Research and Quality; 2015, http://www.ahrq gov/professionals/quality-patient-safety/qualityresources/tools/literacy-toolkit/healthlittoolkit2. html. Accessed January, 2017.

11. Weiss, BD. Health literacy and patient safety: help patients understand [DVD]. Chicago: AMA Foundation, 2007.

12. Weiss BD, Mays MZ, Martz W, et al. Quick assessment of literacy in primary care: the newest vital sign. Ann Fam Med. 2005;3(6):514522 .
13. Kirk JK, Davis SW, Hairston J, Melius K, Marion GS. Medical student health literacy perspectives and experiences. J Fam Med Dis Prev. 2015;1:018. http://clinmedjournals.org/ articles/jfmdp/journal-of-family-medicine-anddisease-prevention-jfmdp-1-018.pdf. Accessed January 2017.

14. Greenwald AG, McGhee DE, Schwartz JL. Measuring individual differences in implicit cognition: the implicit association test. J Pers Soc Psychol. 1998;74(6):1464-1480.

15. Heider JD, Skowronski JJ. Improving the predictive validity of the implicit association test. N Am J Psychol. 2007;9:53-76.

16. Sriram N, Greenwald AG. The brief implicit association test. Exp Psychol. 2009;56(4):283294

17. McCann WJ, Marion GS, Davis SW, Crandall SJ, Hildebrandt CA. Applied relaxation and applied mindfulness (ARAM): A practical and engaging approach for mind-body regulation training in medical education. Ann Behav Sci Med Educ. 2013;19(2):10-15.

18. American Diabetes Association. Standards of Medical Care in Diabetes - 2011. Diabetes Care 2011;34 (Suppl. 1).

19. American Diabetes Association. Standards of Medical Care in Diabetes - 2012. Diabetes Care 2012;35 (Suppl. 1)

20. American Diabetes Association. Standards of Medical Care in Diabetes - 2013. Diabetes Care 2013;36 (Suppl. 1).

21. American Diabetes Association. Standards of Medical Care in Diabetes - 2014. Diabetes Care 2014;37 (Suppl. 1).

22. American Diabetes Association. Standards of Medical Care in Diabetes - 2015. Diabetes Care 2015;38 (Suppl. 1)

23. Marion GS, Hildebrandt CA, Davis SW, Marín AJ, Crandall SJ. Working effectively with interpreters: a model curriculum for physician assistant students. Med Teach. 2008;30(6):612617.

24. US Department of Health and Human Services. Health Literacy. HRSA. http://www.hrsa. gov/publichealth/healthliteracy. Accessed January 2017.

25. IBM SPSS Statistics for Windows. Version 22.0. Armonk, NY: IBM Corp; 2013. 